\title{
Cut off values of bone mineral density defining postmenopausal women with bone fractures
}

\author{
Gian Galeazzo Riario-Sforza, Cristoforo Incorvaia, Antonella Scazzoso, Tiziana Travisi, \\ Fabio Nitti, Mario Fumagalli
}

\begin{abstract}
Objectives-To define cut off values of bone mineral density (BMD), measured at different forearm sites by single photon absorptiometry, that discriminated postmenopausal women who have had fractures from those who have not, in order to provide an index of fracture risk for screening purposes.

Methods-BMD values were measured at distal third radius (DTR) and ultradistal radius (UDR) sites in two groups of postmenopausal women. Group $1 \quad(n=398)$ had not suffered fractures, and group 2 $(n=354)$ had appendicular fractures. Results were evaluated using receiver operating characteristic (ROC) curves.

Results-BMD values were significantly greater $(p<0.001)$ at both sites in group 1 . Weight was lower in group 2 than in group $1(p<0 \cdot 001)$. The BMD cut off value was $0.596 \mathrm{~g} / \mathrm{cm}^{2}$ at DTR (sensitivity $63 \%$, specificity $72 \%$ ), and $0.310 \mathrm{~g} / \mathrm{cm}^{2}$ at UDR (sensitivity $80 \%$, specificity $80 \%$ ). Values of area under ROC curves estimated for UDR were greater than for those DTR (p<0.001).

Conclusion-For screening purposes the BMD cut off value of $0.310 \mathrm{~g} / \mathrm{cm}^{2}$ at the UDR may be useful in identifying women at high risk of fracture in an unselected postmenopausal population. BMD measured at UDR appeared to have a better predictive value than that at DTR.
\end{abstract}

(Ann Rheum Dis 1995; 54: 807-810)

The diagnosis of osteoporosis and its therapeutic follow up depend on the detection of a reduction in the bone mineral density (BMD) that is a commonly used parameter of bone strength. ${ }^{12}$ Values are determined by various absorptiometric methods, including single photon (SPA), ${ }^{3}$ dual photon (DPA), ${ }^{4}$ and the more recent dual energy $x$ ray absorptiometry (DXA)..$^{5}$ SPA measures peripheral bone density, usually assessed at different forearm sites, while DPA and DXA can measure BMD at vertebral and femoral neck sites. ${ }^{6}$ Some studies $^{78}$ have reported a better efficiency of DPA and DXA in predicting vertebral or hip fractures because peripheral BMD values may not be related closely enough with the mineral content of the axial skeleton or femoral head; in contrast, a good predictive value has been reported for all kinds of fractures using the SPA technique. ${ }^{9}$
The major clinical feature of osteoporosis is bone fracture, but at present clear cut off values identifying subjects at high risk of fracture do not exist. Instead, the most commonly used criteria are either a decrease in BMD greater than two standard deviations (SD) from the normal mean measured in young premenopausal women, ${ }^{1}$ or the 'fracture threshold' calculated among fracture subjects at the 90 th percentile. ${ }^{10}$ More recently, a World Health Organisation report ${ }^{11}$ defined fracture risk for postmenopausal osteoporosis as a $\mathrm{T}$ score less than $2 \cdot 5$.

The aim of this study was to determine, using receiver operating characteristic (ROC) curves, the cut off BMD value defining those postmenopausal women who had suffered fractures. To do this we compared BMD (measured by SPA at different forearm sites) in two groups of postmenopausal women-with and without bone fractures.

\section{Patients and methods}

PATIENTS

Patients were selected from a population of more than 6500 white Italian women submitted to bone densitometry in the previous six years in the osteoporosis clinic of the Rheumatology/Allergy Unit, Buzzi Hospital, Milan, Italy. A detailed clinical history using a standard questionnaire with all the items commonly used in the assessment of osteoporosis $^{12}$ was obtained from all subjects during the first BMD measurement. Age, height (without shoes) and weight (with indoor clothing) were also recorded at the time of BMD measurement. The enrolled subjects were divided into two groups. Both groups were free from acute or chronic diseases or treatments interfering with bone metabolism. Menopause was defined as starting after the final menstrual period. ${ }^{13}$

Group 1-Postmenopausal women without bone fractures. This group was formed by subjects with no fractures in their clinical history referring consecutively to our clinic to undergo mineralometry by SPA. The inclusion criteria were that they had never suffered bone fractures; and that they had undergone a natural or surgical menopause at least six years earlier.

Overall, 980 patients fulfilled both inclusion criteria; however, for statistical purposes the recuritment was stopped at a number comparable to that entering group 2 .

Group 2-Postmenopausal women with bone fractures. This group was formed by all 
eligible subjects selected from the original population. Inclusion criteria were a clinical history of at least two appendicular fractures, regardless of site, postmenopause and after minimal or no trauma, and that they had undergone a natural or surgical menopause at least six years earlier.

Only patients producing well documented medical reports concerning the occurrence of fractures were enrolled in the study. Patients with only one fracture were excluded.

BONE DENSITY MEASUREMENT

All BMD measurements, expressed in $\mathrm{g} / \mathrm{cm}^{2}$, were carried out in the non-dominant forearm at both the distal third of radius (DTR) and the ultradistal radius (UDR) as described previously, ${ }^{6}$ using a Norland N2780X3 single photon bone densitometer (Norland Instruments, Fort Atkinson, Wisconsin, USA). To assess the precision of our instrument, we performed duplicate measurements of BMD at both DTR and UDR sites six times a year for three years in the same eight healthy subjects. The variability (coefficient of variation) of the instrument was $2 \cdot 6 \%$ for DTR and $2.3 \%$ for UDR, which is in agreement with previously reported values of about $2 \cdot 5 \% .^{14}$

NORMAL REFERENCE VALUES

We measured BMD at both DTR and UDR bone sites in a group of healthy premenopausal women in order to determine normal reference values in our population. The group was formed by white Italian subjects chosen among medical and nursing hospital staff and their female relatives. These women had to satisfy the following inclusion criteria: no bone fracture ever; no consumption of alcohol and tobacco; adequate dietary calcium intake habit; ${ }^{15}$ regular menses; no acute or chronic diseases or treatment interfering with bone metabolism.

\section{STATISTICAL ANALYSIS}

Differences in each group concerning demographic and anthropometric data, BMD values measured at DTR and UDR, and areas under the ROC curves were analysed by Student's $t$ test for unpaired data.

Optimal cut off values of bone density were determined by ROC curve analysis. ${ }^{16}{ }^{17}$ ROC curves were calculated using the computer program LABROC1, modified from RSCOREII by C Metz and colleagues, Department of Radiology and the Franklin McLean Memorial Research Institute, University of Chicago, USA. This program gives a maximum likelihood estimation of an ROC curve from a set of continuously distributed data with an automated calculation of the operating points on the ROC curve, each corresponding to a single critical test result value. The optimal discriminator position was established by plotting the values of sensitivity and 1-specificity obtained from each point and choosing the one at the shortest distance from ideal point represented by a sensitivity of 1 and a 1-specificity of 0 . Finally, the area under each ROC curve and its SD were estimated by the calculation of the non-parametric trapezoidal rule, as described previously by Hanley and McNeil. ${ }^{18}$

\section{Results}

A total of 752 subjects (398 in group 1 and 354 in group 2) were enrolled in the study. The postmenopausal period ranged from six to 41 years (mean 17.4 (7.5) years) in group 1 and from six to 45 years (mean $17 \cdot 2(7 \cdot 7)$ years) in group 2. BMD values measured at both sites were significantly greater in women who had not suffered fractures than in those who had fractures $(p<0.001)$. Mean weight was significantly less in group 2 than in group 1 $(p<0.001)$, but the other anthropometric and demographic parameters examined were well matched.

Table 1 lists the patients' mean age, height, weight, and BMD values recorded at the DTR and UDR sites, and the statistical significance of differences in BMD values between groups. It also displays anthropometric and BMD parameters measured at DTR and UDR sites in a reference group formed by 282 healthy premenopausal women. These data were comparable to those previously reported by Halioua et $a l^{19}$ using the same Norland apparatus.

Table 2 shows the number, kind, and prevalence of fractures, and the figure displays the different ROC curves obtained measuring BMD at DTR and UDR. Optimal cut off BMD values obtained analysing ROC curves were $0.596 \mathrm{~g} / \mathrm{cm}^{2}$ (sensitivity $72 \%$, specificity $63 \%$ ) at the DTR and $0.310 \mathrm{~g} / \mathrm{cm}^{2}$ (sensitivity $80 \%$, specificity $80 \%$ ) at the UDR site. Areas under the ROC curves were 0.7356 (SD 0.0211) at

Table 1 Characteristics of subjects studied

\begin{tabular}{|c|c|c|c|c|c|}
\hline & \multirow{2}{*}{$\begin{array}{c}\text { Age } \\
\text { (yr) }\end{array}$} & \multirow{2}{*}{$\begin{array}{l}\text { Height } \\
(\mathrm{cm})\end{array}$} & \multirow{2}{*}{$\begin{array}{l}\text { Weight } \\
\text { (kg) }\end{array}$} & \multicolumn{2}{|l|}{ Bone density $\left(\mathrm{g} / \mathrm{cm}^{2}\right)$} \\
\hline & & & & $D T R$ & $U D R$ \\
\hline $\begin{array}{l}\text { Group } 1(n=398) \\
\quad \text { (postmenopausal, no fractures) }\end{array}$ & $\begin{array}{l}65 \cdot 0(7 \cdot 3)^{\star \star \star} \\
{[52-80]}\end{array}$ & $\begin{array}{l}159 \cdot 8(6 \cdot 5) \\
{[142-179]}\end{array}$ & $\begin{array}{l}63 \cdot 5(10 \cdot 0)^{\star}+十 \dagger \\
{[41-96]}\end{array}$ & $\begin{array}{l}0.613(0.080)^{\star \star \star}+f \dagger \\
{[0.303-0.798]}\end{array}$ & $\begin{array}{l}0.341(0.068)^{\star \star \star}+十+ \\
{[0.165-0.538]}\end{array}$ \\
\hline $\begin{array}{l}\text { Group } 2(\mathrm{n}=354) \\
\quad \text { (postmenopausal, fractures) }\end{array}$ & $\begin{array}{l}65 \cdot 2(7 \cdot 8) \star \star \star \star \\
{[49-84]}\end{array}$ & $\begin{array}{l}159 \cdot 8(6 \cdot 7) \\
{[142-181]}\end{array}$ & $\begin{array}{l}60 \cdot 2(9 \cdot 5)^{\star} \\
{[38-90]}\end{array}$ & $\begin{array}{l}0.575(0.090)^{\star \star \star} \\
{[0.341-0.827]}\end{array}$ & $\begin{array}{l}0.285(0.062)^{\star \star \star} \\
{[0.132-0.507]}\end{array}$ \\
\hline $\begin{array}{l}\text { Reference group }(n=282) \\
\quad \text { (premenopausal, healthy) }\end{array}$ & $\begin{array}{l}39 \cdot 2(3 \cdot 6) \\
{[35-45]}\end{array}$ & $\begin{array}{l}160 \cdot 0(5 \cdot 5) \\
{[145-175]}\end{array}$ & $\begin{array}{l}61 \cdot 8(9 \cdot 6) \\
{[45-89]}\end{array}$ & $\begin{array}{r}0.712(0.056) \\
{[0.487-0.872]}\end{array}$ & $\begin{array}{r}0.438(0.056) \\
{[0.252-0.578]}\end{array}$ \\
\hline
\end{tabular}

Values are mean $(\mathrm{SD})$ [range] $. \mathrm{DTR}=$ Distal third of radius; UDR $=$ ultradistal radius. Statistically significant difference: ${ }^{\star} \mathrm{p}<0 \cdot 05$, $\star \star \star \mathrm{p}<0.001$ compared with reference group; $+\dagger+\mathrm{p}<0.001$ compared with group 2 . 
Table 2 Number and prevalence of appendicular fractures in postmenopausal women with fractures

\begin{tabular}{ll|ll|ll}
\hline $\begin{array}{l}\text { Number of } \\
\text { fractures }\end{array}$ & $\begin{array}{l}\text { Prevalence } \\
(\%)\end{array}$ & $\begin{array}{l}\text { Type of } \\
\text { fracture }\end{array}$ & $\begin{array}{l}\text { Prevalence } \\
(\%)\end{array}$ & $\begin{array}{l}\text { Type of } \\
\text { fracture }\end{array}$ & $\begin{array}{l}\text { Prevalence } \\
(\%)\end{array}$ \\
\hline 2 & $66 \cdot 2$ & Arm & $57 \cdot 2$ & Leg & $42 \cdot 8$ \\
3 & $17 \cdot 7$ & Colles & $63 \cdot 4$ & Hip & $16 \cdot 3$ \\
4 & $7 \cdot 4$ & Humerus & $17 \cdot 4$ & Patella & $10 \cdot 5$ \\
5 & $3 \cdot 5$ & Elbow & $15 \cdot 2$ & Tibia & $20 \cdot 7$ \\
6 & $1 \cdot 8$ & Hand & $2 \cdot 9$ & Fibula & $12 \cdot 8$ \\
7 & $1 \cdot 4$ & Finger & $1 \cdot 1$ & Ankle & $21 \cdot 3$ \\
8 & $1 \cdot 7$ & & & Foot & $13 \cdot 2$ \\
& & & & Toe & $5 \cdot 2$ \\
\hline
\end{tabular}

the DTR and $0.8577(0.0192)$ at the UDR $(\mathrm{p}<0.001)$.

\section{Discussion}

Reduced bone mass in osteoporosis is responsible for an impairment of bone biomechanical resistance, leading to an increased risk of fractures secondary to little or no trauma in asymptomatic subjects. ${ }^{1}$ The incidence of fractures and the social cost of this disease could be reduced if methods were available for early detection of the population at risk, enabling prevention of bone loss by appropriate treatment.

BMD measurement at various sites is at present the most widely used non-invasive technique of assessing bone mass. ${ }^{6}$ Vertebral and femoral values are reported to have a better predictive value for fracture risk, especially at the site assessed, ${ }^{10}$ so that both sites must be measured in order to achieve a complete evaluation. ${ }^{20}$ Peripheral BMD measurement, available at low cost and with low exposure to radiation, has a good predictive value for various kinds of fractures as reported in prospective studies. ${ }^{921}$ As fracture risk is related to absolute bone density and cannot be compared with normal subjects of the same age and gender, ${ }^{22}$ currently available BMD threshold values are based either on bone density distribution in premenopausal normal subjects, with fracture risk recognised as $\mathrm{BMD}$ less than $2 \mathrm{SD}$ from the mean, ${ }^{1}$ or on fracture threshold estimation in fracture subjects at the 90 th percentile. ${ }^{10}$ More recently, Kanis et $a l^{11}$ in a WHO technical

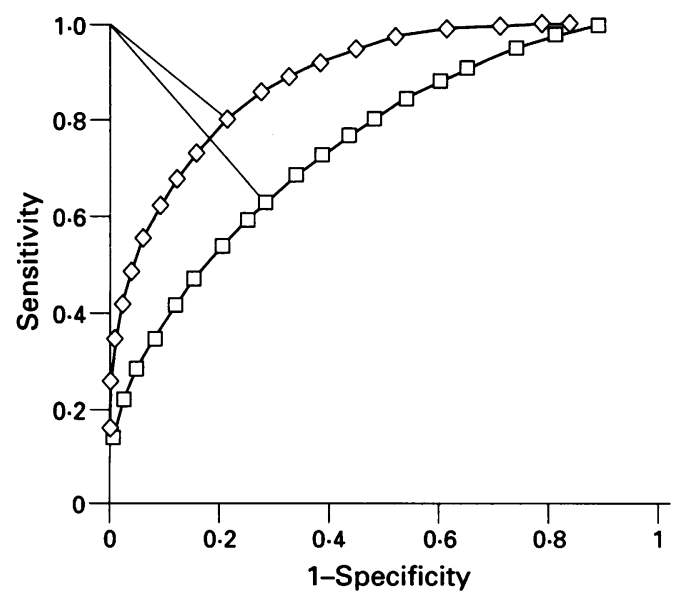

Receiver operating characteristic (ROC) curves obtained measuring bone mineral density at distal third of radius $\square)$ and ultradistal radius $(\diamond)$ bone sites in the groups studied. Solid lines join the ideal point that provides both sensitivity and specificity equal to 1 (1-specificity equal to

0 ) with the closest operating point on the curve-considered to be the threshold value. report defined fracture risk for postmenopausal osteoporosis as a $\mathrm{T}$ score less than $2 \cdot 5$.

In the present study we compared two strictly selected groups of women, both groups postmenopausal by at least six years, one having suffered fractures and the other free of fractures. Those who had not suffered fractures had significantly greater $B M D$ values and weighed significantly more than those who had fractures, which is in agreement with a previously reported direct correlation between weight and bone density. ${ }^{12}$ These two groups were well matched for the other demographic and anthropometric parameters we examined. Our aim was to estimate the optimal BMD cut off value, measured by SPA at two peripheral sites, able to discriminate at best those subjects at high risk for fracture using the method of analysis of ROC curves. This method derives from information theory ${ }^{16}$ and has increasingly been taken up in the medical field in recent years.

It is known ${ }^{23}$ that in both cross sectional and prospective studies an underestimation may occur in evaluating the risk of fracture expressed by $B M D$ values. As longitudinal studies need a long period of observation to avoid false negatives arising from a short follow up, we performed a cross sectional study in order to recruit a sufficient number of postmenopausal patients with appendicular fractures to provide statistically reliable BMD cut off values. During our selection of women with fractures, we recruited patients with at least two fractures as a true expression of a high risk of bone fracture, because the occurrence of a single fracture may have been related to the causative trauma alone, regardless of the BMD value.

Our data show that mean BMD value at both sites examined (DTR, UDR) were significantly lower in postmenopausal women with fractures than in their non-fractured couterparts $(p<0.001)$, but optimal cut off values calculated comparing fractured and nonfractured groups showed different sensitivity and specificity values between the two anatomical sites. The cut off values measured at DTR had sensitivity and specificity of 63 and $72 \%$, respectively, which would be considered unsatisfactory as threshold values for therapeutic decisions. In contrast, while the same statistical difference was found between the BMD values of the two groups at the UDR bone site, the associated ROC curve was of a different shape with a significantly greater area index. For this site, the optimal cut off value of $0.310 \mathrm{~g} / \mathrm{cm}^{2}$ had acceptable sensitivity and specificity values of approximately $80 \%$, and may therefore be used in screening BMD values to reveal the risk of fracture, as it successfully identified postmenopausal women with fractures. This value corresponds to about 2SD below the mean measured in our reference group of healthy subjects, and agrees well with the reported $50-100 \%$ increase in the incidence of fractures for a decrease of at least 1SD in bone mass. ${ }^{24}$ Other age related factors such as bone quality or postural instability may be important in specific bone fractures, such as 
hip fracture ${ }^{25}$ none, however, is a satisfactory predictor for future risk of fracture, ${ }^{26}$ while a single $\mathrm{BMD}$ measurement performed at the UDR by single photon absorptiometry may be suitable to predict fracture risk in a nonselected postmenopausal population and may identify the level of bone mass below which appropriate treatment is indicated. A similar approach in preventive treatment was reported using a cut off range of $1 S D$ below the normal mean, ${ }^{27}$ but a single numerical value can be more convenient to use in clinical practice than a range of variation. In the present study a more effective assessment of BMD was observed at UDR than at DTR, suggesting that a better predictive value is obtained if the bone site for measurement is as distal as possible. An explanation for this may be that our study included women in menopause for a period ranging from six to 45 years, so that both postmenopausal osteoporosis (type onemainly affects trabecular bone) and senile osteoporosis (type two-affects both cortical and trabecular bone) were represented. ${ }^{28} \mathrm{~A}$ decrease in BMD at UDR may be more evident than at DTR because in these two positions the percentage of cortical and trabecular bone varies at the two sites. ${ }^{29}$

This study considered only patients affected by appendicular fractures; thus the cut off values we cite are applicable to screening nonspinal fracture risk; however, BMD assessment at radius sites has been reported to have a good predictive value even for spinal fractures. ${ }^{11} \mathrm{~A}$ further consideration is that our results can be applied to Norland instruments 2780 series only. Cross calibration of peripheral bone densitometers is possible using a phantom, but the results obtained with other appliances may be different because the phantom does not account exactly for all in vivo anatomical factors determining instrument variability. ${ }^{30}$

In conclusion, an optimal BMD cut off value of $0.310 \mathrm{~g} / \mathrm{cm}^{2}$, corresponding to sensitivity and specificity values of approximately $80 \%$, was found at the UDR site; this value could be a useful tool for the clinician in screening women of postmenopausal age at high risk of fracture among an unselected population. The UDR site appeared to yield BMD values that had better predictive value of fracture risk than those obtained at the DTR site of measurement.

1 Nordin B E C. The definition and diagnosis of osteoporosis. Calcif Tissue Int 1987; 40: 57-8.

2 Lindsay R, Tohme J. Estrogen treatment of patients with established postmenopausal osteoporosis. Obstet Gynecol 1990; 76: 1-6.

3 Johnston C C Jr, Smith D M, Nance W E, et al. Evaluation of radial bone mass by the photon absorption technique. Excerpta Med Int Congr Ser 1973; 270: 28-36.
4 Raymakers J A, Hoekstra O, Van Putten J. Osteoporotic fracture prevalence and bone mineral mass measured with CT and DPA. Skeletal Radiol 1986; 15: 191-7.

5 Mazess R, Collick B, Trempe J, Barden H, Hanson J Performance evaluation of a dual-energy X-ray bone densitometer. Calcif Tissue Int 1988; 43: 189-91.

6 Genant H K, Faulkner K G, Gluer C C. Measurements of bone mineral density: current status. Am $\mathcal{F}$ Med 1991; 91 (suppl 5B): 49-53.

7 Johnston C C, Melton R J, Lindsay R. Clinical indications for bone mass measurements. F Bone Miner Res 1989; 4 (suppl 2): 1-28.

8 Mazess $\mathrm{R}$ B, Peppler W W, Chesney $\mathrm{R}$ W, Lang $\mathrm{T}$ A, Lindgren U, Smith E. Do bone measurements on the radius indicate skeletal status? $f$ Nucl Med 1984; 25: radius

9 Gardsell P, Johnell O, Nilsson B E. Predicting fractures in women by using forearm bone densitometry. Calcif Tissue Int 1989; 44: 235-42.

10 Riggs B L, Wahner H W, Seeman E, et al. Changes in bone mineral density of the proximal femur and spine with aging. Differences between the postmenopausal and senile osteoporosis syndromes. 7 Clin Invest 1982; 70: 716-23.

11 Kanis J A, Meunier P, Burkhardt P, et al. Assessment of fracture risk and its application to screening for postmenopausal osteoporosis. Report of a WHO study pouptIn: WHO Technical Report Series No 843. Geneva: World In: Whalth Organisation, 1994: 1-129.

12 Hansen M A, Overgaard $\mathrm{K}$, Riis B J, Christiansen C. Potential risk factors for development of postmenopausal osteoporosis-examined over a 12-year period. Osteoporo Int 1991; 1: 95-102.

13 Utian W H. Overview on menopause. Am f Obstet Gynecol 1987; 156: 1280-3.

14 Hui S L, Wiske P, Norton J A, Johnston C C Jr. Prospective study of change of bone mass with age in postmenopausal women. 7 Chronic Dis 1982; 35: 715-25.

15 Heaney R P, Gallagher J C, Johnston C C, Neer R, Parfit A M, Whedon G D. Calcium nutrition and bone health in elderly. Am f Clin Nutr 1982; 36: 986-1013.

16 McNeil B J, Hanley J A. Statistical approaches to the analysis of receiver operating characteristic (ROC) curves. Med Decis Making 1984; 4: 137-50.

17 Gerhadt W, Keller H. Evaluation of tests data from clinical studies. I. Terminology, graphic interpretation, diagnostic strategies, and selection of sample groups. Scand $\mathcal{F}$ Clin Lab Invest 1986; (suppl) 181: 5-42.

18 Hanley J A, McNeil B J. The meaning and use of the area under a receiver operating characteristic (ROC) curve. Radiology 1982; 143: 29-36.

19 Halioua L, Anderson J J B. Age and anthropometric determinants of radial bone mass in premenopausal Caucasian women: a cross-sectional study. Osteoporosis Int 1990; 1: 50-5.

20 Bouillon R, Burckhardt P, Christiansen C, et al. Consensus development conference: prophylaxis and treatment of osteoporosis. Osteoporos Int 1991; 1: 114-7.

21 Wasnich R D, Ross P D, Heilbrun L K, Vogel J M Prediction of postmenopausal fracture risk with use of bone mineral measurements. Am f Obstet Gynecol 1985 153: 745-51.

22 Need A G, Nordin B E C. Which bone to measure? Osteoporos Int 1990; 1: 3-6.

23 Kanis J A, Adami S. Bone loss in the elderly. Osteoporos In 1994; 4 (suppl 1): 59-65.

24 Johnston C C, Slemenda C W, Melton L J. Clinical use of bone densitometry. $N$ Engl f Med 1991; 324: 1105-9.

25 Cummings S R, Black D M, Nevitt M C, et al. Appendicular bone density and age predict hip fracture in women. fAM $A$ 1990; 263: $665-8$.

26 Cummings S R, Nevitt M C. A hypothesis: the causes of hip fractures. F Gerontol Med Sci 1989; 44: 107-11.

27 Tosteson A N A, Rosenthal D I, Melton L J III, Weinstein M C. Cost effectiveness of screening white women for osteoporosis: bone densitometry and hormone replacement therapy. Ann Int Med 1990; 113: 594-603.

28 Riggs B L, Melton L J, Wahner.H W. Heterogeneity of involutional osteoporosis: evidence for two distinct osteoporosis syndromes. In: Frame B, Potts J T Jr, eds. Clinical disorders of bone and mineral metabolism. Amsterdam: Excerpta Medica, 1983; 337-42.

29 Schlenker R A, Von Seggen W W. The distribution of cortical and trabecular bone mass along the lengths of radius and ulna and the implications for in vivo bone mass measurement. Calcif Tissue Res 1976; 20: 41-52.

30 Pearson J, Ruegsegger P, Dequeker J, et al. European semianthropomorphic phantom for the cross-calibration of pheripheral bone densitometers: assessment of precision accuracy, and stability. Bone Miner 1994; 27: 109-20. 